Boštjan BUGARIČ

\title{
Strukturnovsebinske preobrazbe slovenskih obalnih mest
}

Strukturne preobrazbe slovenskih obalnih mest so rezultat vsebinskih razvojnih strategij, ki so jih narekovali različni mestni akterji v različnih zgodovinskih obdobjih. Zaradi procesa industrializacije je prostor obalnih mest dobil novo strukturo v obliki industrijskih objektov. Danes ostajajo te strukture brez ustreznih vsebin in predstavljajo degradirana območja mesta, ki jih poskuša na vsak način uravnavati interes kapitala. Povojno obdobje funkcionalizma je zaznamovalo prizadevanje za ustvarjanje prostorskih možnosti za potrebe delavskega razreda, ki se je naseljeval v novih stanovanjskih soseskah. Iz industrijskih struktur, ki so se širile v horizontalo, se je v šestdesetih letih 20. stoletja pojavila nova tipologija stanovanjskega nebotičnika, ki se je začela dvigovati v vertikalo. Obdobje po tranziciji je v obalni prostor vneslo splošno kaotično stanje na ravni organizacije prostora, saj so posege izvajali po željah kapitala in manj na podlagi strokovnih usmeritev. Urbanizem kot stroka ni dovolj prožen za uravnavanje hitrih preobrazb oblik kapitala, zato se ta neomejeno oblikuje čez vse meje mesta.

KLUČNE BESEDE: industrializacija, funkcionalizem, slovenska obala, privatizacija.
The structural transformations of Slovenian coastal cities are a form of content development strategies that have been dictated by different city actors throughout the history. Because of the process of industrialisation, the coastal region adopted a new structure in the form of industrial structures. Today, these structures are left without appropriate contents and present degraded areas of the city that are subject to the interest of the capital. The post-war period of functionalism attempted to introduce in the area the conditions for social reformation of the social structure, architects were designing for the needs of the working class, which inhabited the newly built residence areas. In the sixties of the $20^{\text {th }}$ century, a new typology of residential tall buildings, which began to rise vertically, emerged from horizontal industrial structures. At the level of organisation of space, the period after transition brought in the coastal space a widespread state of chaos, as spatial interventions were made on the basis of the interest of capital and to a lesser degree on the basis of expert guidelines. Urbanism as a discipline is not flexible enough to regulate the swift transformations of the forms of capital. As a result, the capital is spreading unrestrictedly across all limits of the city.

KEY WORDs: industrialization, functionalism, Slovenian coast, privatization.

visokošolskimi strukturami. To je svojo pravo podobo dobilo šele z ustanovitvijo Univerze na Primorskem v devetdesetih letih dvajsetega stoletja. Tedaj se je začelo prestrukturiranje gospodarstva iz družbene lastnine v zasebno. Posledice so vidne v propadanju velikih industrijskih obratov zaradi nekonkurenčnosti, čedalje bolj pa v javnem prostoru mest. Velik vpliv nanj ima tudi proces turistifikacije ${ }^{[2]}$ mestnih jeder, ki je zlasti opazen v slovenskih obmorskih mestih.

Zaradi neustrezne in zastarele urbanistične zakonodaje in pomanjkanja metodoloških izhodišč in meril prostorskega razvoja imajo vplivi kapitala pri urbanističnih posegih precej proste roke. Predolge in neučinkovite priprave prostorskih planov in nezmožnost sprejemanja razgibanih strategij in načinov prostorskega planiranja so razvojno politiko usmerile $\mathrm{v}$ plemenitenje kapitala in s tem celotno območje podredile urejanju na podlagi in 
presoji profita finančnega zaslužka. Prostorsko planiranje je na lokalni ravni usmerjeno v izdelavo dolgoročnih prostorskih dokumentov, zaradi česar ni mogoče zaznavati posledic, ki jih na okolju pušča neusmerjena rast kapitala. $V$ tem kontekstu sta planerski stroki odvzeti odprtost in demokratičnost odločanja, ki v planerski proces razvoja vključujeta vse mestne akterje, in ne samo akterjev elite.

Stanje treh slovenskih obalnih mest kaže na neuravnoteženo prostorsko planiranje, čedalje večje so razlike med socialnimi sloji v mestu, veča se prepad med bogatimi in revnimi. Zaradi gentrifikacijskih ${ }^{[3]}$ procesov se spreminja struktura uporabnikov mestnih jeder. Bivalne razmere $\mathrm{v}$ njih so postale $\mathrm{v}$ obdobju po osamosvojitvi države neustrezne predvsem zaradi šibkega vlaganja $v$ prenovo. Uporabniki mestnega jedra so bili večinoma iz nižjih družbenih slojev, ki so živeli na margini.

Prepletenost gospodarskega razvoja in politične volje je prispevala $\mathrm{k}$ oblikovanju podobe mest na slovenski obali. Organizacija prostora je bila odvisna od vloženega gospodarskega kapitala in je oblikovala različne formalne relacije med uporabniki in mestom. Za industrializacijo so ostali veliki objekti, ki so danes zaradi nerabe skupaj s celotnim pozidanim območjem postali degradirana območja mesta. Tranzicija je v urbani prostor prinesla velika nakupovalna območja, ki s svojo potrošniško usmerjenostjo degradirajo vsebinska razmerja mesta. Mesta potrošnje se razvijajo ločeno od mestnih jeder in nimajo $\mathrm{z}$ njimi nikakršne povezave. To dodatno prispeva $\mathrm{k}$ degradaciji vsebin $\mathrm{v}$ mestnih jedrih. Neuravnoteženo stanje mest se veča tudi zaradi kapitalskih usmeritev razvojne politike, ki ne upošteva dolgoročnih razvojnih ciljev.

\section{Preobrazbe srednjeveške strukture kot posledica industrializacije; 1900}

V obdobju industrijske revolucije so se zaradi novih vsebinskih potreb spremenili srednjeveška struktura in odnosi $v$ mestih. Nove funkcije so se začele koncentrirati $\mathrm{v}$ mestnem jedru ${ }^{[4]}$, $\mathrm{s}$ tem so se ponujale nove možnosti zaposlovanja in doseganja višjega življenjskega standarda. Vse to je povzročilo migracije s podeželja v mesta. Že Mumford (1969) govori o naglem naraščanju števila prebivalcev $\mathrm{v}$ mestih in navaja, da je leta 1800 večja svetovna mesta naseljevalo manj kot milijon prebivalcev, petdeset let pozneje pa so $\mathrm{v}$ določenih mestih presegli milijon. Do leta 1900 se je na svetu razvilo enajst metropol z več kot milijonom prebivalcev ${ }^{[5]}$. Trideset let pozneje je bilo na svetu sedemindvajset takih metropol. Zaradi prevelikega zgoščevanja vsebin in prevelikega naseljevanja mestnih jeder so se veliki obrati in tovarne začeli oblikovati zunaj mestnih jeder.

Industrializacija je pustila posledice tudi na slovenskih obalnih mestih. Najočitnejše so v Izoli, ki se danes zaradi preobrazbe vsebin ukvarja s problemom degradiranih površin nekdanjih industrijskih obratov. Pri Kopru ne moremo govoriti o klasičnem procesu industrializacije, saj gre za poseben primer urejanja luške infrastrukture, ki je v kratkem časovnem obdobju daleč presegla merilo mestnega jedra. Najmanjši vpliv industrializacije je zaznaven $\mathrm{v}$ Piranu, saj se je industrija $\mathrm{v}$ tem delu umikala proti Portorožu.

Na spremembo mestnega jedra Kopra je pošteno vplival razvoj pristanišča, ki je bilo ustanovljeno leta 1957. Z zasipavanjem plitvine med kopnim in otokom se je izoblikoval prostor za pristaniško infrastrukturo. Z nasipom proti izlivu Rižane na ankaranski strani je postal popolnoma izoliran Škocjanski zatok, izliv Badaševice pa je bil preusmerjen v Semedelski zatok. Danes je Luka Koper edino slovensko pristanišče in ima 1600 hektarjev površin (Cifrek, 2002). Po velikosti presega mestno merilo in je eden izmed osrednjih predstavnikov gospodarske moči, s samim mestom pa nima nobene vsebinsko-prostorske povezave. Historična aglomeracija mestnega jedra je zato s težavo konkurirala vsebinskim in prostorskim potrebam pristanišča. Potrebe sodobnega bivanja pa so korenito spremenile mestno podobo koprskega otoka. Bernik (1968) ugotavlja, da se je sesulo antropocentrično merilo historične aglomeracije, saj je bilo mesto podvrženo stihijskemu planiranju brez celovite prostorske vizije.
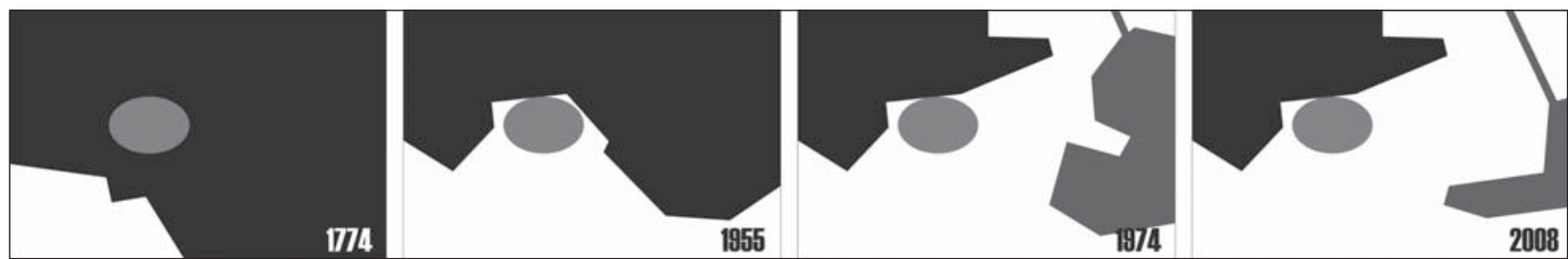

Slika 1: Razvoj mesta in luke na primeru Kopra. (Vir: prirejeno po: Cifrek, 2002) 
Popolnoma drugače je industrijske vsebine razvijalo mesto Izola. Večinoma je industrijska dejavnost segla $\mathrm{v}$ neposredno bližino ali celo $\mathrm{v}$ samo mestno jedro. Izola je prav tako kot Koper nekoč ležala na otoku in se je s kopnim povezala šele v 19. stoletju. Na povezovanje je med drugim zelo vplival razvoj solin na območju med otokom in kopnim. Zaradi pospešene industrializacije in gradnje novih industrijskih obratov je mestno jedro Izole v 19. stoletju začelo dobivati novo podobo. Prispevek industrializacije je bilo precej močneje čutiti kot v Kopru ali Piranu, saj je bila konec 19. stoletja na severozahodnem delu polotoka postavljena prva tovarna za predelavo in konzerviranje rib ob Jadranskem morju. Delovanje tovarne Ampelo, ki je nastala kot posledica posredovanja tujega kapitala $\mathrm{v}$ mestno jedro, je leta 1879 pripomoglo $\mathrm{k}$ razvojnemu zagonu v mestu. Tovarno je postavila francoska družba Societe generale francaise de conserves alimentaries, pozneje pa se je iz nje razvila tovarna Delamaris. V tem obdobju so s pomočjo avstrijskega in italijanskega kapitala na kopenskem delu Izole zgradili štiri tovarne vse do Simonovega zaliva (Bernik, 1968). Pospešena industrializacija Izole je prispevala k spremembi socialne strukture uporabnikov mestnega jedra. Zasutje že omenjenega jarka med otokom in kopnim je omogočilo novo organizacijo in razvoj mestnih dejavnosti, za razvoj katerih v mestnem jedru ni bilo dovolj prostora. Industrijski razvoj je vplival tudi na mestno jedro Izole, in čeprav osrednji del arhitekturno ni bil znatneje načet, se posledice opažajo na socialni in družbeni strukturi uporabnikov. V gradbeni strukturi so na obodnem delu mesta opazne modernizirane fasade, v številnih primerih pa se kažejo tudi posledice neustrezne rabe barvne skale, ki s sredozemskim prostorom nima nobene povezave.

Kot že omenjeno, je najmanjši vpliv industrializacije občuten v Piranu, ker so v 20. stoletju v Portorožu postavili tovarno mila, ki je za glavno surovino črpala morsko sol. Struktura piranskega organizma je namreč s svojo konfiguracijo terena onemogočala gradnjo velikih struktur. Industrijski obrati so se zato oblikovali zunaj mestnega jedra, na obrežnem delu ob cesti proti Portorožu.

\section{Velikopotezni funkcionalizem ali nova družbena utopija; povojno obdobje}

Prenova stavbnega fonda je bila v povojnem obdobju vsekakor temeljna družbenopolitična naloga, ki se je oblikovala na temeljih funkcionalistične miselnosti CIAM-ovega kritičnega diskurza. Potreba po novi stanovanjski gradnji je pospešila ideološko usmerjenost funkcionalistične miselnosti. Navezava na politično usmeritev se posebno v Primorju kaže v formalnih posegih mest, sprva $\mathrm{v}$ obliki razraščanja stanovanjskih sosesk, pozneje pa celovitih urbanističnih posegih v mestu. Investbiro je leta 1966 izdelal Regionalni načrt slovenske obale. To je bila prva in celovita ureditev slovenske in istrske obalne regije oziroma tudi prva ureditev neke krajine $\mathrm{v}$ takratnem jugoslovanskem prostoru. Odgovorni urbanist pri izdelavi celovitega plana slovenske obale od Debelega rtiča do Sečovelj je bil Edo Mihevc. Čebron Lipovec (2007) opredeli Mihevčeve intervencije v mestih na štiri kategorije: prva so posegi na starih objektih, druga posegi na zaščitenih objektih, tretja kategorija so nove arhitekturne intervencije, četrta pa obsega oblikovanje parkirnih območij. Na urbanistični ravni je njegovo delo vsekakor pomemben prispevek k celovitemu urejanju slovenske obale, saj je funkcionalizem povezal s tradicionalnimi rešitvami, ki so bile na prostoru že preizkušene. Z uporabo tradicionalnih detajlov, ki jih je vključil v sodobno zazidavo, je oblikoval osnovo kritičnega regionalizma in ga vsebinsko interpretiral po svoje. Tukaj se kot primer lahko izpostavi njegov perforirani betonski nosilec, uporabljen za balkonske ograje ali pergole, ter perforirani strešni venec, ki ga je izpeljal iz primorskega motiva podstrešnih mezaninskih oken.

Kljub velikopoteznim posegom in celovitemu reševanju urbane problematike Obale pa so bili premalo upoštevani vsebinski procesi, ki so na razvoj prostora vplivali po svoje. V doktrini funkcionalističnega razumevanja urejanja prostora velja očitno dejstvo, da se s formalno ureditvijo načelno uredi tudi vsebinska razmerja in delovanje akterjev. Košir (2000: 82) zelo ustrezno opredeli problem, ko pravi, da "funkcionalizem res naredi dve grobi napaki; ker pridiga vero, da se da že samo z obliko zazidave spremeniti tudi sestav družbe, in ker se v svoji teoriji pretirano togo opira samo na racionalne, vulgarno funkcionalne sestavine, tako da vse iracionalno in tradicionalno potlači v drugi plan«. Funkcionalizem je kot gibanje poskušal reševati socialne probleme mest, gradil pa je na popolnoma formalističnih prijemih prenove in premalo z usmerjanjem vsebinske raznovrstnosti v mestu. Izenačevanje družbene strukture $\mathrm{v}$ enakovrednih objektih je prispevalo $\mathrm{k}$ izenačevanju potreb po vsebinah mesta, kar pa je prispevalo $\mathrm{k}$ manjšanju pestrosti mestnih uporabnikov. V tem kontekstu se je predvsem v Kopru z gradnjo stanovanjske gradnje potrdila Rossijeva (1982) klasifikacija funkcionalizma, ki pravi, da se poskuša iz modela kapitalistične hiše ${ }^{[6]}$ prek parakapitalistične hiše $\mathrm{e}^{[7]}$ ustvariti socialistično ${ }^{[8]}$ hišo. Tako se je začela socialna reforma, ki je oblikovala precej enotno vsebinsko ponudbo za uporabnika mesta. 
Raznovrstnost na urbani ravni ponudbe mesta zamenja enakopravnost, kar popolnoma poenoti in poenostavi urbane vsebine.

Ta proces se je začel tudi zaradi političnih dogodkov po letu 1954, ko je slovenska obala s priključitvijo Trsta Italiji izgubila svoje gospodarsko in politično središče. Z urbanizacijo obalnih mest se je začel tudi velik migracijski proces - zaradi potrebe po novi delovni sili naj bi priliv delavcev in izobražencev iz Slovenije in drugih držav Jugoslavije pospešil urbanizacijo obalnih mest. Tako naj bi obalno območje ostalo neprekinjen pas, ki ima dobro obdelano turistično-gostinsko ureditev, ne upoštevajoč vsebinskih in komunikacijskih navezav ponudbe turizma na dejavnosti v zaledju Obale. Vsa tri obalna mesta so seveda oblikovala značaj na podlagi določenih dejavnosti; Koper je zaradi lege in bližine državne meje z organizacijo pristanišča prevzel osrednjo vlogo celotnega Primorja, Izola je razvijala ribiškoturistične vsebine, ki jih je $\mathrm{v}$ osemdesetih let 20 . stoletja preglasila industrija, Piran pa je ostal edini, ki se je ohranil kot ključen turistični kraj in je edinstven primer ohranjenega strnjenega primorskega mesta per se.

Posegi, ki so jih po vojni planirali na slovenski obali, so bili zaradi socialistične usmerjenosti sistema označeni za politične. Nove stanovanjske potrebe so usmerjale gradnjo stanovanjskih sosesk, ki so nadomeščale buržujsko meščansko arhitekturo mesta. Odnos do upravljanja strukture mesta se je iz kapitalističnega preusmeril v socialističnega. Zaradi prejšnje industrializacije sta Koper in Izola izgubila prvotni značaj ribiških mest in se usmerila predvsem na gradnjo novih stanovanj. »Socialni program, demografske spremembe in slabo materialno stanje obstoječega stavbnega fonda so določali obseg in kvaliteto novogradenj" (Koselj, 1997: 44). Gradilo se je veliko novih stanovanjskih sosesk, kot so Semedela v zaledju Kopra (1961), verižne hiše v Piranu (1960), naselje montažnih hiš v Šalari (Koper, 1962), in poseben tip turističnih naselij, kot so bungalovi v Luciji in Strunjanu (1960-62). Poseben primer Mihevčevega delovanja pa je vsekakor vpeljava nove tipologije stolpnic $\mathrm{v}$ mestno jedro Kopra, ki imajo tudi poseben ideološki pomen in naj bi predstavljale novo mestno obzidje, dominanto, ki konkurira mestnemu zvoniku. Kot ugotavlja Koseljeva (1997), so višinski poudarki odsev tržno usmerjenega gospodarstva, zaradi katerega je narasla cena mestnih površin. Posledice so opazne na mestnih silhuetah, ki so začele dobivati nove oblike višinskih zazidav. Ne da so stolpnice vizualno korenito posegle $\mathrm{v}$ strukturo starega mestnega jedra, ampak so s priseljenci večinoma delavskega razreda osiromašile potrebo po raznovrstnosti vsebin $\mathrm{v}$ mestnem jedru. S takšnim »čiščenjem« mesta se ne strinjajo niti teoretiki, kot je Jacobs (1961), ki trdi, da urbanizma ne moremo enačiti $z$ umetnostjo. Njen predlog prenove starih mest ni kot pri funkcionalistih zazrt $\mathrm{v}$ nove radikalne posege, ki prinašajo tudi nove vsebine, ampak se spogleduje s programi samoorganizirane prenove, ki ponudi uporabniku urbanizem s človeškim obrazom. V tem kontekstu je pomembno, da urbanizem ne sledi samo investicijam kapitala, ampak da planiranje mesta upošteva tudi želje uporabnikov in njihove potrebe.

\section{Degradacija urbanizma kot posledica tranzicije; 1990}

V primorskih mestih se občuti odsotnost participativnega urbanizma. Neuravnoteženost umeščanja vsebin $\mathrm{v}$ urbani in pretirani posegi $\mathrm{v}$ naravni prostor so pripomogli $\mathrm{k}$ pretiranemu stereotipiziranju prostora. Zaradi komercialnega usmerjanja vsebin na ravni javnega prostora pa ta $\mathrm{v}$ mestnem jedru izgublja svoj osnovni pomen. Procesi, ki so formalno in vsebinsko preobrazili definicijo mesta, segajo tako že v industrijsko obdobje, kar je jasno vidno na sliki 2. Tranzicija iz klasičnega industrijskega mesta prek fordističnega $\mathrm{v}$ postfordistično metropolo je $\mathrm{v}$ mestu oblikovala nove vsebine in jih razpršila po prostoru. Osnova razpršene strukture mesta lahko bolje deluje, če ima ustrezno komunikacijsko dostopnost in povezanost. Kjer so nove transportne oblike povezale območja, so pripomogle k širitvi mesta, drugje pa so se zaradi odsotnosti prometne komunikacije oblikovala zapuščena območja. Mestno jedro, ki je imelo včasih osrednjo vlogo, je postalo poslovno oziroma upravno birokratsko središče. Na obrobju so začele nastajati nove organizacijske oblike, ki so med seboj ločene po funkciji. Tam so območja mesta potrošnje z nakupovalnimi središči, tematskih parkov, industrijskih območij, tehnoloških parkov in novih oblik bivanja $\mathrm{v}$ izoliranih zaprtih stanovanjskih soseskah. ${ }^{[9]}$

Podoba sodobnega mesta se tako izoblikuje glede na hitri pretok kapitala, ki usmerja življenje. Včasih je bilo mestno jedro glavni nosilec identitete celotnega mesta. Danes se zunaj mestnih jeder oblikujejo mesta potrošnje $\mathrm{z}$ večinoma komercialnimi vsebinami, ki pritegnejo čedalje več porabnikov. Mestno jedro zaradi neustreznih odločitev stroke ali politike ne ustvarja ugodnih razmer za razvoj novih vsebin. V njem ostajajo osamljeni akterji, ki so marionete kapitalistične ureditve peščice bogatih. Na podlagi njihovih odločitev se uravnava celoten pretok kapitala in s tem usmerja tudi fizični razvoj mesta. Pomembno vlogo pri prostorskem odločanju imajo akterji iz segmentov 

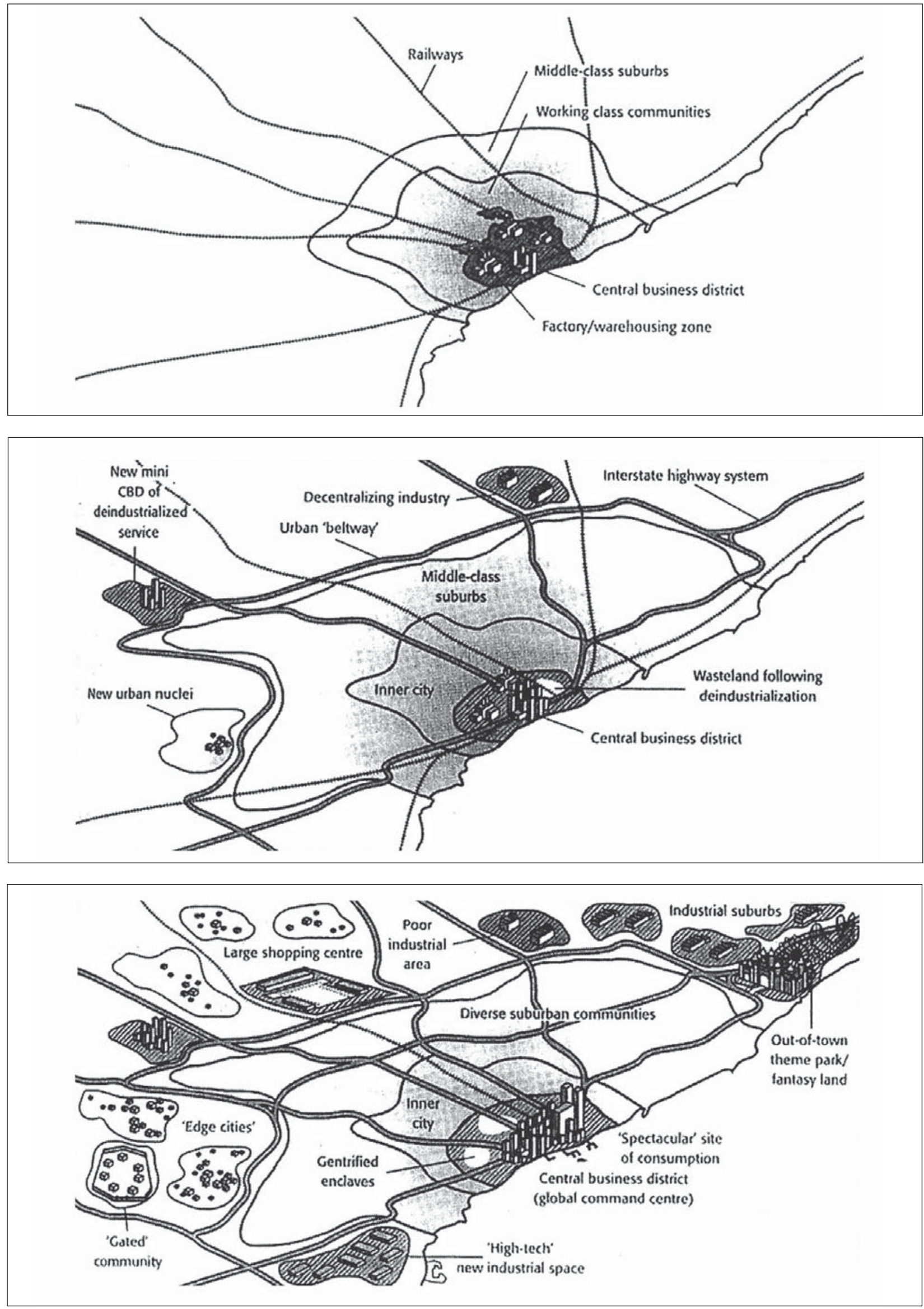

Slika 2: Preobrazba iz mesta s centralno zasnovanimi vsebinami v mesto z razpršenimi vsebinami. (Vir: Carmona in dr., 2003: 30) 
politične javnosti. Reševanje problematike temelji na političnih odločitvah. Pri odločanju akterjev dobivajo prednost vnosi kapitala, ki dolgoročno ne prinesejo podlage za kakovosten razvoj prostora. Zapostavljen je razvoj kulturnih vsebin, ki so ključni kazalnik stopnje družbenega razvoja.

In kam so ti procesi preobrazbe mest pripeljali obalna mesta v Sloveniiji Kakšne so posledice vnosa kapitala $\mathrm{v}$ javni prostor in kako se kažejo neuravnoteženi posegi urbanega planiranja? Za pozidavo vseh treh mest veljata neustrezen vnos novih struktur $\mathrm{v}$ mestno tkivo in neustrezna raba barvnega kolorita, ki naj bi bil vezan na sredozemski prostor. Na robovih historičnih mestnih jeder se oblikujejo novi tipi megastruktur, ki ustvarjajo zanimivejša prizorišča in s tem praznijo mestna jedra. Turistifikacija je zaznavna v Piranu, kjer za njegove vsakodnevne uporabnike ni ustrezne ponudbe. To je posebno očitno zunaj turistične sezone, ko je mesto precej izpraznjeno. Izola in Koper se srečujeta s procesi gentrifikacije, zaradi visokih cen se načrtno zamenjuje družbena struktura $\mathrm{v}$ mestnem jedru. Koper se sicer počasi plemeniti z univerzitetnimi programi in tako dobiva kritično število uporabnikov, ki za svoje potrebe zahtevajo dodatne družbene vsebine. Zaradi kapitalskih vnosov se je na mestnem obrobju oblikovalo strnjeno območje potrošnega mesta, ki zavzema prvi plan mestne vedute. Izola se ukvarja z vprašanjem prestrukturiranja opuščenih industrijskih obratov. Potrebe po novih stanovanjih za trg lahko ta zemljišča, ki so v samem mestnem jedru ali njegovi neposredni bližini, preobrazijo v gosto zazidana območja z gosto stopnjo poseljenosti, kar lahko dolgoročno prinese spremembe na ravni javnega prostora. Za preprečevanje izginjanja javnega prostora je treba razvijati raznovrstnost aktivnosti, ki spodbujajo obisk določenih območij $\mathrm{v}$ mestu. Potrošniška družba spodbuja pojav komercialnih dogodkov na mestnem obrobju, hkrati pa sili aktivnosti v mestnem jedru h komercializaciji. »Kapitalizem in moderna doba je obdobje, v katerem se je $\mathrm{z}$ izginotjem svetega in duhovnega globoko skrita materialnost vseh stvari končno mokra in drgetava dvignila k dnevni luči; in jasno je, da je sama kultura ena izmed tistih reči, katerih fundamentalno materialnost zdaj ne le jasno vidimo, temveč ji tudi ne moremo ubežati« (Jameson, 2001: 156).

Optimalna rešitev, ki bi omogočila povezovanje akterjev in uporabnikov, je sistemska preobrazba orodja za uravnavanje prostorskih planov. Pomembno je, da se pri odločanju in oblikovanju mestnih vsebin oblikuje povezava med neodvisnimi skupinami civilne družbe (nevladne organizacije, neodvisni strokovnjaki) in mestno oblastjo, ki jim mora omogočiti svobodno delovanje. Akcijsko delovanje lahko pripo- more $\mathrm{k}$ dvigu ravni dogajanja $\mathrm{v}$ izpraznjenih in osiromašenih mestnih območjih in $\mathrm{k}$ večji odzivnosti javnosti na urbano problematiko. Pri vsem skupaj je najpomembnejša komunikacija med vpletenimi akterji, saj »nobeno organsko izboljšanje ni mogoče brez reorganizacije procesov, funkcij in namenov ter brez ponovne porazdelitve prebivalstva $\mathrm{v}$ enote, ki pospešujejo dvotirno občevanje, razmerje med menoj in teboj in lokalno nadzorstvo nad lokalnimi potrebami« (Mumford, 1969: 791). Kos (2006) govori o reševanju krize prostorskega planiranja s pomočjo strateškega planiranja, ki bi zlasti na slovenski obali pripomoglo $\mathrm{k}$ večji transparentnosti in odprtosti postopkov planiranja. Tako lahko po Kosu (2006) različni akterji poskušajo pridobivati družbeno podporo za svoje razvojne perspektive. V tej luči se lahko zanašamo na spremembe, ki jih prinaša takšno planiranje: pomeni večjo raznovrstnost akterjev v nasprotju z enim upravljavcem prostora, uvaja nedokončane operacije, ki sprejemajo spremembe, in se s tem laže prilagaja razvojnim procesom ter omogoča odprtost odločanja na podlagi zahtev soodvisnih akterjev. Tudi Goličnikova (2006) trdi, da je pri iskanju kazalcev in vrednot kakovosti bivanja nujen pogled na javni prostor $z$ različnih uporabniško prostorskih vidikov hkrati, kar ustvarja medsebojen proces med uporabniki in fizičnim prostorom oziroma okoljem dogodkov. V vsem tem pa je ključni in osnovni korak, po katerem se bodo lahko obalna mesta razvijala, nujna reorganizacija komunikacij, predvsem uvajanje novih in raznovrstnih modelov javnega transporta, ter spodbujanje t. i. »mehke« mobilnosti. Pri organizaciji večje kakovosti življenja $\mathrm{v}$ mestih je treba spodbujati vsebinsko povezovanje mest med seboj in z zaledjem. Na ravni mest lahko multimodalna vozlišča pripomorejo $\mathrm{k}$ prestrukturiranju prometa. S tem bi dosegli večjo povezanost regije, odpravili problem parkiranja $\mathrm{v}$ ožjih mestnih središčih ter pripomogli k zmanjševanju onesnaženosti, ki jo povzroča čedalje večja uporaba avtomobilov na Obali. V tem kontekstu je treba dodatno ozaveščati uporabnike o različnih možnostih mobilnosti in uvajanju strategij za nove oblike javnega transporta.

\section{Sklep}

Obravnava treh slovenskih obalnih mest $\mathrm{v}$ treh zgodovinskih obdobjih prikazuje, kako družbeni in gospodarski vplivi spreminjajo prostorske odnose $\mathrm{v}$ mestih. Vsako obdobje pušča za seboj fizične strukture, ki so v naslednjem zgodovinskem obdobju prostorsko neustrezne. Industrijski obrati se tako danes $\mathrm{v}$ mestih pojavljajo kot degradirana in neizkoriščena območja, funkcionalistični 
arhitekturni in urbanistični posegi pa so zaradi ideoloških in družbenih prvin brez mestotvornih vsebin. Nakupovalne strukture, nastale v obdobju tranzicije, sledijo podobnim razvojnim trendom, kot so se zgodili v ZDA. Gre za poskuse vsebinske preobrazbe teh območij, ki so večinoma nastali kot posledica kapitalskega prevzemanja zemljišč na območju mesta in njihove komercializacije. Ti procesi v ZDA že potekajo, ker je tam zgodovinski razvoj potrošnih mest že napredoval, saj se je začel že pred petdesetimi leti. Komercializacija pa čedalje bolj zajema tudi evropska mesta. Prostorski posegi $\mathrm{v}$ obdobjih industrializacije in funkcionalizma so arhitekturne zasnove predvidevali v mestnem jedru ali njegovi neposredni bližini, zdaj pa se potrošne megastrukture širijo na obrobje. Praznjenje mestnega jedra prinaša veliko negativnih posledic: zaradi nerabe so objekti v mestnem jedru prepuščeni fizični degradaciji, občutno pa se kaže tudi pomanjkanje vsebinskih povezav. Obalna mesta lahko zato v prihodnosti postanejo cilj postopne turistifikacije in gentrifikacije. Ti bi formalno sicer uredili degradirana mestna območja, vsebinska in družbena prenova pa je vprašljiva, saj bi akterji v mestu delovali za plemenitenje kapitala in ustvarili nove vsebine, namenjene le enemu tipu uporabnikov, kar pa povzroča izgubo vsebinske pestrosti mesta. Javni prostor bi se zaradi odnosov med uporabniki čedalje bolj privatiziral in elitiziral.

Dr. Boštjan Bugarič, uni. dipl. inž. arh., asistent z doktoratom Univerza na Primorskem, Znanstveno-raziskovalno središče Koper E-pošta: bostjan.bugaric@guest.arnes.si

\section{Opombe}

[1] Obravnava se tri večja obalna mesta, in sicer Koper, Izolo in Piran.

[2] Turistifikacija je merilo prevlade turistične dejavnosti $v$ mestu, katere bistvo je neselektivna prostorsko-funkcionalna preobrazba prostorov in objektov za namene turistične in prostočasne ponudbe (Hočevar, 1998).

[3] Gentrifikacija pomeni akcijsko delovanje pri vračanju srednjih in višjih socialnih slojev prebivalstva $\vee$ stara mestna jedra in dele mest s problematično demografsko strukturo. Hočevar (1998: 85) jo opiše kot »proces fizične asanacije, nove izgradnje in socialno-slojevske preobrazbe, izjemoma tudi popolne populacijske zamenjave. Bistvo tega koncepta je, da se z močnimi kapitalskimi investiranji v nižjeslojevskih in/ali imigrantskih stanovanjskih predelih starih mestnih jeder ustvarijo pogoji za transformacijo v kvalitetno bivanjsko področje, kamor se seli del višjih družbenih slojev.«

[4] Mestno jedro obsega območje zgodovinskega dela mesta, kjer naj bi se združevale osnovne mestne funkcije.
[5] Te metropole so bile Berlin, Chicago, New York, Philadelphia, Moskva, Petrograd, Dunaj, Tokio, Kalkuta, London in Pariz (Hudnik, 2002).

[6] Kapitalistično hišo lastniki oddajajo. Vse v njej je podrejeno produkciji dobička (Rossi, 1982)

[7] Parakapitalistična hiša je zgrajena za eno družino, ki lahko oddaja celotno nadstropje (Rossi, 1982).

[8] Socialistična hiša predstavlja po Rossiju (1982) nov tip zazidave v socialističnih deželah, kjer ni več zasebne lastnine.

[9] Gated community, ograjena skupnost oziroma zaprta soseska, je območje naseljevanja višjih slojev prebivalstva v mestih. Gre za primer fizične segregacije prebivalstva, kjer so bivalni predeli višjih slojev fizično ograjeni od kriminala in nasilja ulice.

\section{Viri in literatura}

Bugarič, B. (2006) Univerza in mesto; univerzitetne vsebine kot generator družbenega dogajanja. Doktorska disertacija. Ljubljana, Univerza v Ljubljani, Fakulteta za arhitekturo.

Bernik, S. (1968) Organizem slovenskih obmorskih mest: Koper, Izola, Piran. Piran, Mladinska knjiga.

Carmona, M. in dr. (2003) Public places - urban spaces; The dimensions of urban design. London, Architectural press.

Cifrek, I. (2002) Urejanje krajine sodobnih prometno logističnih terminalov na primeru Koper (diplomsko delo). Ljubljana, Biotehniška fakulteta, Oddelek za krajinsko arhitekturo.

Čebron Lipovec, N. (2007) Modern Architecture in Historical City Centres: Case Study on Edo Mihevc in Koper and Valorisation for Reuse. Leuven, Master's Degree thesis for Raymond Lemaire Internacional Centre for Coneservation.

Goličnik, B. (2006) Vedenjski zemljevidi ljubljanskih trgov in parkov: Novi izzivi in pogledi na načrtovanje in urejanje prostora. Ljubljana, Zbirka Urbani izziv - publikacije.

Hočevar, M. (1998) Analiza revitalizacijske problematike koprskega mestnega jedra; fizični prostor in družbene vsebine. Annales, Series historia et sociologia, 8(12), str. 79-94.

Hudnik, Š. (2002) Mobilna arhitektura in možnosti njene uresničitve v realnem svetu: bioelektronska telesa. Doktorska disertacija. Ljubljana, Univerza $\checkmark$ Ljubljani, Fakulteta za arhitekturo.

Jacobs, J. (1961) The Death and Life of Great American Cities. London, Jonatan Cape.

Jameson, F. (2001) Postmodernizem. Ljubljana, Društvo za teoretsko psihoanalizo, Analekta.

Kos, D. (2003) Postmoderno prostorsko planiranje? Teorija in praksa 40(4), str. 647-657.

Koselj, N. (1997) Arhitektura 60-ih let v Sloveniji; kontinuiteta ideje. Arhitektov bilten - posebna izdaja, 25, str. 6-52.

Košir, F. (2004) Med strukturalizmom in dekonstruktivizmom. Prostorske znanosti za 21. stoletje. Ljubljana, Fakulteta za gradbeništvo in geodezijo, Interdisciplinarni podiplomskih študij prostorskega in urbanističnega planiranja.

Košir, F. (2000) Kako so minevali »novi časi« ali stanovanjsko okolje kot kompozicijski pojem. Izbrani članki 1970/1985. Ljubljana, Fakulteta za arhitekturo.

Mumford, L. (1969) Mesto v zgodovini. Ljubljana, Državna založba Slovenije.

Rossi, A. (1982) The Architecture of the City. Massachusets, The Institute for Architecture and Urban Studies. 